\title{
Long-term results of external valvuloplasty in adult patients with isolated great saphenous vein insufficiency
}

\author{
Atilla Sarac' \\ Artan Jahollari' \\ Sureyya Talay' \\ Sevket Ozkaya ${ }^{2}$ \\ Ertugrul Ozal' \\ 'Department of Cardiovascular \\ Medicine, Samsun Medical Park \\ Hospital, Samsun, Turkey; ${ }^{2}$ Department \\ of Pulmonary Medicine, Faculty of \\ Medicine, Bahcesehir University, \\ Istanbul, Turkey
}

\author{
This article was published in the following Dove Press journal: \\ Clinical Interventions in Aging \\ 5 April 2014 \\ Number of times this article has been viewed
}

\begin{abstract}
Objective: The aim of this study is to present our 7-year results of external valvuloplasty for isolated great saphenous vein (GSV) insufficiency.

Methods: External valvuloplasty was applied in 83 patients with isolated GSV insufficiency. Follow-up consisted of venous color duplex scanning performed on the first postoperative day, the first postoperative month, and then annually. Valvular insufficiency, venous reflux, and venous thrombosis formation in the saphenofemoral junction were the main outcomes.

Results: A complete clinical and radiological healing was observed in 50 patients $(60 \%)$. In 13 cases (15.6\%), a secondary surgical treatment was performed consisting of vena saphena magna high ligation/stripping and varicose vein excisions, mainly due to severe and progressive vena saphena magna valvular insufficiency and clinical persistence of symptoms. Eight patients (9.6\%) developed superficial vein thrombosis, and only one patient (1.2\%) developed deep vein thrombosis. Contact was lost from 32 patients (38.5\%) for different reasons.
\end{abstract}

Conclusion: External valvuloplasty is an effective surgical technique for selected cases of isolated GSV insufficiency without extensive varicose dilatations. This alternative method can be safely administered as an alternative to high ligation and conventional GSV stripping.

Keyword: vein, saphenous, insufficiency, external valv, valvuloplasty, varicosis

\section{Introduction}

Lower-extremity venous insufficiency is one of the most common chronic disorders of the population. It effects life quality and comfort and comprises a cosmetic problem at the same time. Drug therapy and compression stockings are used to relieve symptoms in early phases, while surgery is applied in advanced cases. Different surgical procedures have been described, including great saphenous vein (GSV) ligation and stripping, GSV radiofrequency ablation, and GSV endovenous laser ablation. ${ }^{1}$ Reconstruction procedures such as repair or transplantation of incompetent valves of deep veins, direct saphenofemoral junction (SFJ) plication, and external vein valve wrapping did not gain large popularity among physicians and are less applied. ${ }^{2,3}$

External valvuloplasty (EVP) is a reconstructive surgical modality preferred in cases with dilation and reflux of the GSV due to SFJ or proximal GSV valve incompetency. A Gore $^{\circledR}$ (Gore and Associates, Inc., Flagstaff, AZ, USA) external valve support is a supporting device consisting of polytetrafluoroethylene (PTFE)-covered nitinol frames and is used for EVP of the GSV. It aims to increase the coating surface and restore valve competency by external support.

This procedure has been used in our Cardiovascular Surgery Clinic at Bahcesehir University since 2001 to treat isolated GSV insufficiency patients without extensive
Correspondence:Atilla Sarac

Department of Cardivascular Surgery, Medicalpark Hospital, Samsun, Turkey

Email saracatilla@gmail.com 
varicose veins and lack of deep system involvement. As limited literature regarding durability of this procedure exists, we report our long-term results, including color duplex scanning and clinical data.

\section{Materials and methods}

All patients were preoperatively evaluated with color duplex scanning, and isolated valve insufficiency at the SFJ was the main enrolment criterion for EVP. Patients that had concomitant deep venous insufficiency or extensive varicose veins were not included.

In all of the patients, the inguinal region was dissected from the greater saphenous vein trajectory under local anesthesia. The SFJ was examined, and in the level of the valve just distally to this junction, an expanded-PTFE-coated (including a nitinol frame) external valve support (Gore and Associates, Inc.) in appropriate size (small, medium, or large) was placed around the vein. The appropriate diameter of PTFE was calculated with the San Valentino formula, ${ }^{4}$ according to patient's weight and height (Figure 1). All the patients received local anesthesia consisting of a combination of $1 \%$ lidocaine and $0.25 \%$ bupivacaine. Additional sedation with intravenous midazolam was used when necessary. No patient required general anesthesia. The GSV, SFJ, and femoral vein were explored, and 2,500 IU of heparin sulfate was administered. The incompetent valve at the SFJ was localized and embraced circumferentially with the device. Fenestrated interfacing parts of the device were carefully positioned at the valve bulbus, and the device was closed with $7 / 0$ propylene sutures (Figures 2-5). Hemostasis was performed, and incision was closed without drain usage. All the patients received
$150 \mathrm{mg}$ od oral acetyl salicylic acid, $500 \mathrm{mg}$ bid calcium dobesilate, and 20-30 mmHg pressure knee-high compression stockings 6 months postoperatively.

Color duplex scanning was performed on all the patients at the first postoperative day, first postoperative month, and then annually. Absence of reflux, vein patency, functionality of the valve, and deep or superficial vein thrombosis were the primary outcomes.

Results presented in this study are expressed as ratio or mean \pm standard deviation. Differences between categorical variables were analyzed. Continuous parameters were analyzed with Student's $t$-test.

Ethical committee approval was obtained, and all patients received a detailed consent form.

\section{Results}

Between April 2001 and January 2008, 83 patients (26 male and 57 female) with isolated GSV insufficiency underwent EVP. The characteristics of the patients are presented in Table 1. Mean age was $48.7 \pm 11.5$ years (male, 50.9 \pm 3.1 ; female, 45.8 \pm 14.3 ). Comorbidities included diabetes mellitus $(\mathrm{n}=6,7.2 \%)$, hypertension $(\mathrm{n}=10,12 \%)$, smoking $(\mathrm{n}=39$, $46 \%, 19$ male and 20 female), past history of cardiac or major vascular surgery $(n=10,12 \%)$, and COPD $(n=6,7.2 \%)$.

Early and long-term outcomes were analyzed. At the end of the first postoperative month, no re-hospitalization was observed. Inflammation at the surgical incision was noticed in nine patients $(10.8 \%)$ who received ambulatory antibiotic therapy. During the first month, no reoperation due to hemorrhage, major surgical complication, or death was observed. Postoperative mean $( \pm \mathrm{SD})$ follow-up time was $46.4 \pm 28.3$ months

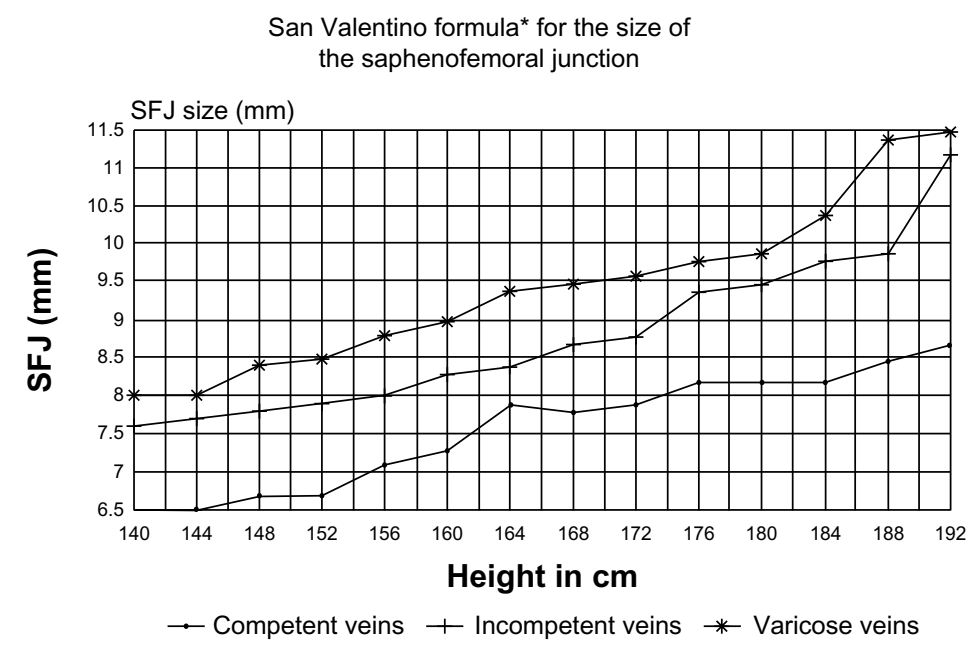

Figure I The San Valentino formula.

Note: $*[$ Height $(\mathrm{cm}) / 2] / 10$.

Abbreviation: SFJ, saphenofemoral junction. 

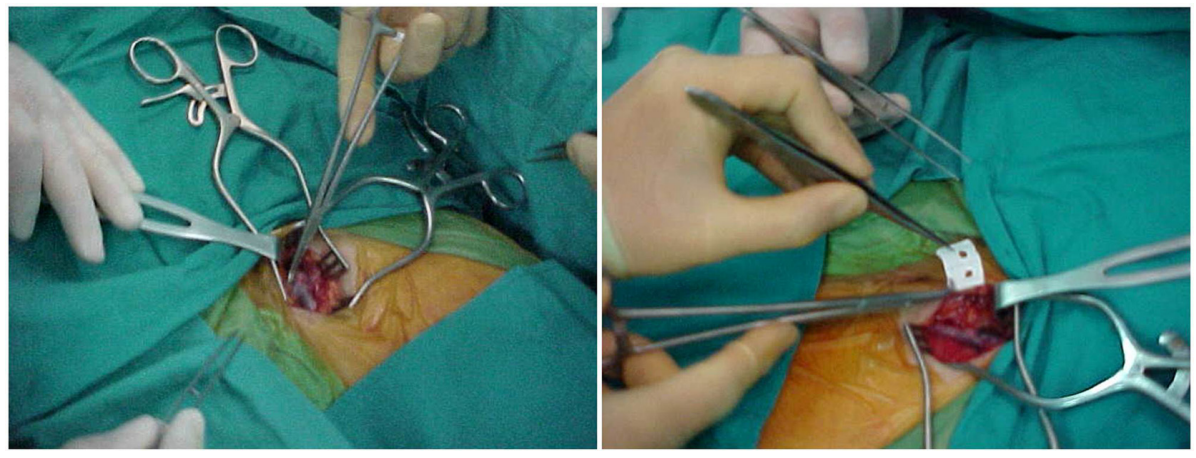

Figure 2 Intraoperative view showing the preparation for attaching external valve.

(1-112 months). A total of 51 patients (61.5\%) were punctually followed for 7 years, while contact was lost with 32 patients (38.5\%) during different periods for various reasons. At the 7 -year follow-up, 50 patients (60\%) showed no complaint and an absence of clinical findings. Superficial vein thrombosis occurred in eight patients (9.6\%) and deep vein thrombosis in one patient (1.2\%). Eighteen patients (21.6\%) showed periodic symptoms including cramps, pain, swallowing, discomfort, and had developed telangiectasia or varicose veins. In five of these patients $(6.0 \%)$, continuous venotonic drug administration and compression stocking therapy was sufficient in relieving symptoms. Thirteen patients (15.6\%) showed progression of symptoms and increased SFJ reflux, and required high ligation and stripping of GSV. Postoperative follow-up data are shown in Table 2.

\section{Discussion}

Various surgical approaches regarding superficial or deep venous insufficiency have been described in the literature. In a surgical era of repair and minimally invasive procedures, GSV protective venous surgery is of great importance. Cases with

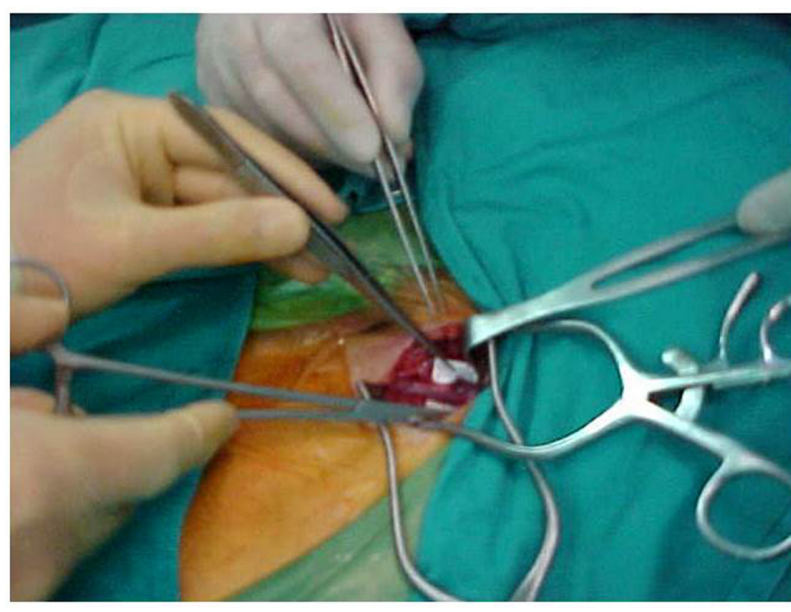

Figure 3 Installing external valve is seen. isolated SFJ incompetency benefit the most from this type of procedure. The main targets of EVP are GSV protection with restoration of normal superficial venous functions, achievement of optimal cosmetic results due to less surgical trauma, and preservation of GSV as a possible graft for future cardiovascular procedures. In addition, considering the anatomical relationship with the deep venous system, a preserved GSV can play a crucial role in saving the extremity during development of deep vein thrombosis. EVP approaches have been a wellstudied phlebology topic. ${ }^{4,5}$ A general consensus, that SFJ valve repair would decrease venous insufficiency symptoms distal to the SFJ, exists. At the same time, it would prevent formation of varicose veins. For this reason, various devices including Dacron-reinforced silicone cuffs (Venocuff ${ }^{\mathrm{TM}}$, Imthage BioResearch Analysis Facility, NSW, Australia), polyethylene terephthalate, and thermomechanically expanded PTFE have been developed. ${ }^{6-9}$ We have used PTFE-covered nitinol frames (Gore and Associates, Inc.) for a long period of time and have not encountered any allergic reaction to the implanted material. The implantation procedure is easy to perform, safe, and can provide satisfying long-term results.

Incandela et $\mathrm{al}^{10}$ in their study have described the same technique of EVS, comparing it with the conventional ligation/stripping. They report extremely satisfying 1-year results of EVS, consisting of reduction of reflux and preservation of venous functions, and underline the benefits compared with the "destructive" effects of conventional ligation/ stripping. One-year results of our study are similar to those of Incandela et al. ${ }^{10}$ We therefore support the application of EVS in selected patients, as it can be at least comparable to but probably better than conventional ligation/stripping. Belcaro et al, ${ }^{6}$ recently published the long-term results of their experience with the Gore external supporting device. Of their patients, $4 \%$ developed SFJ reflux, and of the limbs, $46.9 \%$ developed varices. Our study also showed good durability of the device and satisfying outcomes, as $50(60 \%)$ of the SFJ 


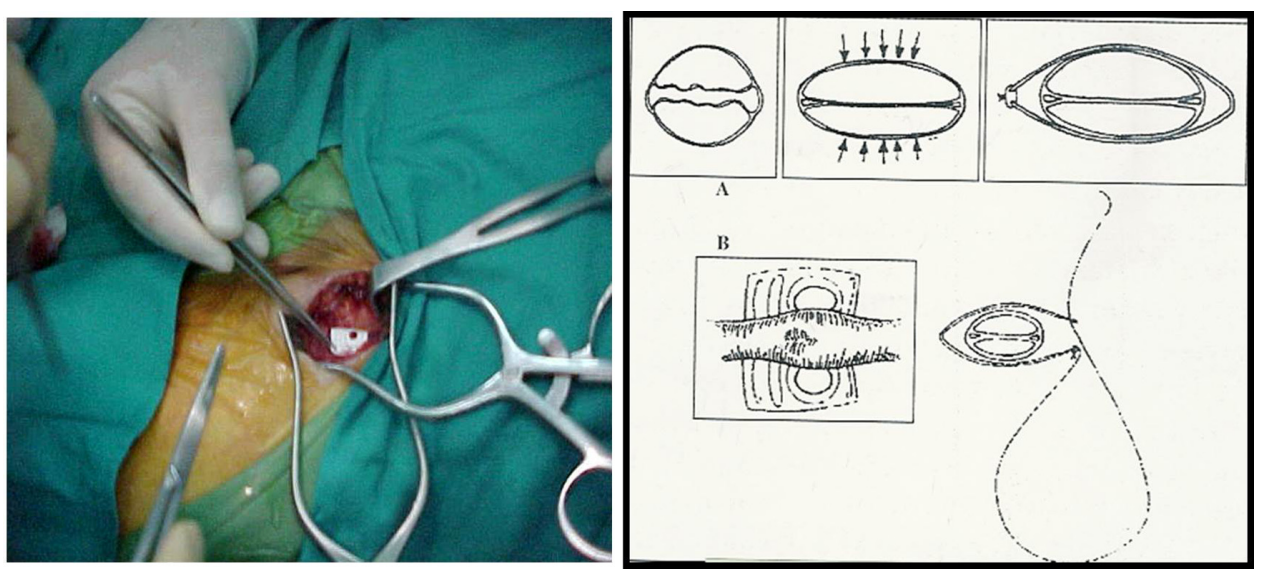

Figure 4 Intraoperative view showing implantation and mechanism of efficacy (A) with technique of the insertion device (B).

valves in our study remained competent at 7 years, and the reoperation rate was low (13 patients, $15.6 \%$ ). It has to be noted that we lost contact with 32 patients (38.5\%), probably asymptomatic, as the symptomatic patients were presenting more frequently for follow-up.

Joh et $\mathrm{al}^{7}$ have also reported encouraging results involving external valvuloplasty for SFJ reflux. They applied external banding valvuloplasty with polyester-tailored mesh in 101 extremities during a period of 10 years and followed GSV diameter and SFJ reflux with color duplex scanning. They observed significant reduction in GSV diameter postoperatively and good 5-year SFJ competency. Similar results were obtained in our study. Preoperative mean vena saphena magna (VSM) diameter $(5.6 \pm 1.1 \mathrm{~mm})$ was significantly reduced $(P<0.01)$ at postoperative first day $(3.1 \pm 1.1 \mathrm{~mm})$, first month $(3.2 \pm 1.0 \mathrm{~mm})$, first year $(3.5 \pm 0.9 \mathrm{~mm})$, third year $(3.8 \pm 1.3$ $\mathrm{mm})$, fifth year $(4.3 \pm 0.9 \mathrm{~mm})$, and seventh year $(4.5 \pm 1.1$

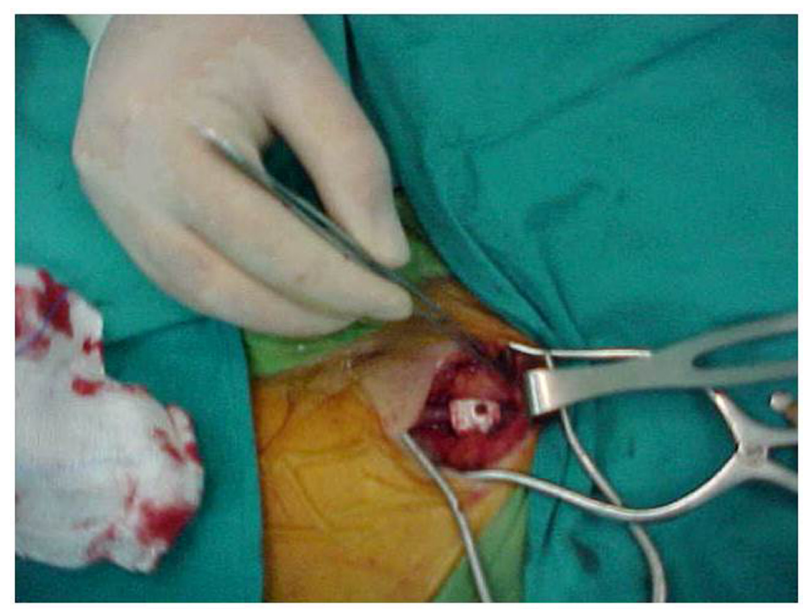

Figure 5 Intraoperative view showing implantation of the device. $\mathrm{mm})$. Joh et $\mathrm{al}^{7}$ reported a thrombosis rate of $12.9 \%$ at 5 -year follow-up, while other authors report different results. ${ }^{11-13} \mathrm{In}$ our study, eight (9.6\%) patients presented with thrombosis of GSV, and one patient (1.2\%) developed deep vein thrombosis. Achievement of satisfying results with the same technique, despite the diversity of the devices or material used, support the effectiveness and durability of EVP.

Controversies exist about the pathogenesis of varicose veins. Some of the studies attribute the venous insufficiency mainly to the disorder of elastic components of the vein wall, while others emphasize valvular incompetence as a major factor. ${ }^{11-15}$ According to the results of our study, restoring valvular competency and function plays an important role. We think that valve repair, by significantly reducing venous reflux and continuity, decreases distal venous pressure and indirectly helps to preserve anatomic elasticity of the wall.

As it has been determined in other studies, ${ }^{16-18}$ multiple factors can affect long-term results of EVS. Continuous pathological process of loss of VSM wall elasticity, interfer-

Table I Characteristics of patients

\begin{tabular}{ll}
\hline Characteristic & \\
Age, mean \pm SD, years & $48.7 \pm$ I I.5 \\
Sex & \\
$\quad$ Male, $n(\%)$ & $26(3 \mathrm{I} .3)$ \\
$\quad$ Female, $\mathrm{n}(\%)$ & $57(68.7)$ \\
Comorbidities & \\
$\quad$ Diabetes mellitus, $\mathrm{n}(\%)$ & $6(7.2)$ \\
Hypertension, $\mathrm{n}(\%)$ & $10(12)$ \\
Smoking, $\mathrm{n}(\%)$ & $39(46)$ \\
COPD, $\mathrm{n}(\%)$ & $6(7.2)$ \\
Major vascular/cardiac surgery, $\mathrm{n}(\%)$ & $10(12)$ \\
\hline
\end{tabular}

Abbreviations: COPD, chronic obstructive pulmonary disease; SD, standard deviation. 
Table 2 Treatment results

\begin{tabular}{|c|c|c|c|c|c|c|c|}
\hline & $\begin{array}{l}\text { I day } \\
\text { after surgery }\end{array}$ & $\begin{array}{l}\text { I month } \\
\text { after surgery }\end{array}$ & $\begin{array}{l}\text { I year } \\
\text { after surgery }\end{array}$ & $\begin{array}{l}2 \text { years } \\
\text { after surgery }\end{array}$ & $\begin{array}{l}3 \text { years } \\
\text { after surgery }\end{array}$ & $\begin{array}{l}5 \text { years } \\
\text { after surgery }\end{array}$ & $\begin{array}{l}7 \text { years } \\
\text { after surgery }\end{array}$ \\
\hline $\begin{array}{l}\text { Full valvular competency } \\
\text { at SFJ, } n(\%)\end{array}$ & $83(100 \%)$ & $80(97.1 \%)$ & 79 (95.1\%) & 71 (85.5\%) & $63(75.9 \%)$ & $5 \mathrm{I}(6 \mathrm{I} .4 \%)$ & $50(60 \%)$ \\
\hline $\begin{array}{l}\text { GSV diameter, } \\
\text { mean } \pm \text { SD }\end{array}$ & $\begin{array}{l}3.1 \pm 1.1 \\
(P<0.01)\end{array}$ & $\begin{array}{l}3.2 \pm 1.0 \\
(P<0.01)\end{array}$ & $\begin{array}{l}3.5 \pm 0.9 \\
(P<0.01)\end{array}$ & $\begin{array}{l}3.6 \pm 1.1 \\
(P<0.01)\end{array}$ & $\begin{array}{l}3.8 \pm 1.3 \\
(P<0.01)\end{array}$ & $\begin{array}{l}4.3 \pm 0.9 \\
(P<0.01)\end{array}$ & $\begin{array}{l}4.5 \pm 1.1 \\
(P<0.01)\end{array}$ \\
\hline $\begin{array}{l}\text { Thrombosis of } \\
\text { superficial veins, } n(\%)\end{array}$ & 0 & 0 & I (I.2\%) & $2(2.4 \%)$ & $2(2.4 \%)$ & $3(3.6 \%)$ & 0 \\
\hline $\begin{array}{l}\text { Thrombosis of } \\
\text { deep veins, } \mathrm{n}(\%)\end{array}$ & 0 & 0 & 0 & 0 & 0 & $\mathrm{I}(\mathrm{I} .2 \%)$ & 0 \\
\hline $\begin{array}{l}\text { Further surgery } \\
\text { (ligation/stripping), n (\%) }\end{array}$ & 0 & $2(2.4 \%)$ & $2(2.4 \%)$ & $3(3.6 \%)$ & $3(3.6 \%)$ & $2(2.4 \%)$ & $\mathrm{I}(\mathrm{I} .2 \%)$ \\
\hline Loss of contact, n (\%) & 0 & $\mathrm{I}(\mathrm{I} .2 \%)$ & $\mathrm{I}(\mathrm{I} .2 \%)$ & 7 (8.4\%) & 15 (I8\%) & $26(31.3 \%)$ & $32(38.5 \%)$ \\
\hline Total, n & 83 & 82 & 82 & 76 & 68 & 57 & 51 \\
\hline
\end{tabular}

Abbreviations: GSV, great saphenous vein; SD, standard deviation; SFJ, saphenofemoral junction.

ence of clinical factors such as thrombosis, upsized EVS, and deterioration of valve functions are among these. In our study, superficial system thrombosis occurred in eight patients, and we think that aggressive downsizing of the SFJ may be an important causative factor. Secondary surgery was required because of increased SFJ reflux, mainly due to valve deterioration.

In conclusion, EVP is an experimental alternative to GSV stripping and may be of benefit in a few selected patients with isolated VSM insufficiency and without widespread varicosities.

\section{Disclosure}

The authors declare no conflict of interest in this work.

\section{References}

1. Kistner RL, Sparkuhl MD. Surgery in acute and chronic venous disease. Surgery. 1979;85(1):31-43.

2. Kistner RL. Surgical repair of a venous valve. Straub Clin Proc. 1968;24: 41-43.

3. Belcaro GV. Plication of the sapheno-femoral junction. An alternative to ligation? Acta Chir Belg. 1989;89(4):305-308.

4. Kim DI, Lee BB, Bergan JJ. Venous hemodynamic changes after external banding valvuloplasty with varicosectomy in the treatment of primary varicose veins. J Cardiovasc Surg. 1999;40(2):567-570.

5. Corcos L, Peruzzi GP, Romeo V, Procacci T, Zamboni P, Dini S. [External valvuloplasty of the sapheno-femoral junction]. Phlebologie. 1991;44(5):497-508. French.

6. Belcaro G, Agus G, Errichi BM, et al. Gore external valve support for superficial saphenous vein incompetence: a 10-year, follow-up registry. Panminerva Med. 2011;53(3 Suppl 1):35-41.
7. Joh JH, Lee KB, Yun WS, Lee BB, Kim YW, Kim DI. External banding valvuloplasty for incompetence of the great saphenous vein: 10 year results. Int J Angiol. 2009;18(1):25-28.

8. Lane R, McMahon C, Cuzzilla M. The treatment of varicose veins using the venous valve cuff. Phlebology. 1994;9:136-145.

9. Schanzer H, Skladany M. Varicose vein surgery with preservation of the saphenous vein: a comparison between high ligation-avulsion versus saphenofemoral banding valvuloplasty-avulsion. J Vasc Surg. 1994;20:684-687.

10. Incandela L, Belcaro G, Nicolaides AN, Agus G, Errichi BM. Superficial vein valve repair with a new external valve support (EVS). Angiology. 2000;51(8):39-53.

11. Corcos L, Peruzzi G, Romeo V, Procacci T. Preliminary results of external valvuloplasty in sapheno-femoral junction insufficiency. Phlebology. 1989;3:197-202.

12. Guarnera G, Furgiuele S, Camilli S. The role of external banding valvuloplasty with the veno cuff in the treatment of primary deep venous insufficiency. Phlebology. 1994;9:150-153.

13. Obitsu Y, Ishimaru S, Furokawa K, Yoshihama I. Histopathological studies of the valves of varicose veins. Phlebology. 1990;5:245-254.

14. Recek C. Conception of the venous hemodynamics in the lower extremity. Angiology. 2006;57(5):556-563.

15. Shami SK, Sarin S, Cheatle TR, Scurr JH, Coleridge-Smith PD. Venous ulcers and the superficial venous system. JVasc Surg. 1993;17: 487-490.

16. Makarova NP, Lurie F, Hmelniker SM. Does surgical correction of the superficial femoral vein valve change the course of varicose disease? J Vasc Surg. 2001;33:361-368.

17. Belcaro G, Christopoulos D, Vasekis S. Correction of superficial venous incompetance with an external Gore-Tex patch applied at the saphenofemoral junction. A randomised study versus ligation of the junction. $J$ Cardiovasc Surg. 1993;34(4):395-398.

18. Berkan Ö, Öztürkcan S, Okuyan B, Marufi M, Doğan K, Hatipoğlu A. Evaluation of venous ulcers. Turk Klin J Med Sci. 1999;19(6): $326-329$.

\section{Dovepress}

\section{Publish your work in this journal}

Clinical Interventions in Aging is an international, peer-reviewed journal focusing on evidence-based reports on the value or lack thereof of treatments intended to prevent or delay the onset of maladaptive correlates of aging in human beings. This journal is indexed on PubMed Central, MedLine, the American Chemical Society's 'Chemical Abstracts Ser- vice' (CAS), Scopus and the Elsevier Bibliographic databases. The manuscript management system is completely online and includes a very quick and fair peer-review system, which is all easy to use. Visit http://www.dovepress.com/testimonials.php to read real quotes from published authors. 